\title{
RNAi-mediated down-regulation of the expression of OsFAD2-1: effect on lipid accumulation and expression of lipid biosynthetic genes in the rice grain
}

\author{
Gopal Ji Tiwari ${ }^{1,2}$, Qing Liư ${ }^{3}$, Pushkar Shreshtha ${ }^{3}$, Zhongyi Li $i^{3}$ and Sadequr Rahman ${ }^{1,2^{*}}$
}

\begin{abstract}
Background: The bran from polished rice grains can be used to produce rice bran oil (RBO). High oleic (HO) RBO has been generated previously through RNAi down-regulation of OsFAD2-1. HO-RBO has higher oxidative stability and could be directly used in the food industry without hydrogenation, and is hence free of trans fatty acids. However, relative to a classic oilseed, lipid metabolism in the rice grain is poorly studied and the genetic alteration in the novel $\mathrm{HO}$ genotype remains unexplored.

Results: Here, we have undertaken further analysis of role of OsFAD2-1 in the developing rice grain. The use of Illumina-based NGS transcriptomics analysis of developing rice grain reveals that knockdown of Os-FAD2-1 gene expression was accompanied by the down regulation of the expression of a number of key genes in the lipid biosynthesis pathway in the $\mathrm{HO}$ rice line. A slightly higher level of oil accumulation was also observed in the HO-RBO.

Conclusion: Prominent among the down regulated genes were those that coded for FatA, LACS, SAD2, SAD5, caleosin and steroleosin. It may be possible to further increase the oleic acid content in rice oil by altering the expression of the lipid biosynthetic genes that are affected in the $\mathrm{HO}$ line.
\end{abstract}

Keywords: Rice bran oil, Triacylglycerol, Oleic acid, FAD2, Transcriptome

\section{Background}

Rice is one of the most important crops for mankind as it provides nearly half of the world's population a source of dietary energy [1]. Apart from starch, rice grains contain a small proportion of lipids (1-4\% of the grain) located mostly in the bran. Rice bran oil (RBO) is extracted from rice bran as a by-product of milling and is commercially available as a food grade vegetable oil $[2,3]$. Triacylglycerols (TAGs) make up about $85 \%$ of the total lipids in RBO, followed by phospholipids $(\sim 6.5 \%)$ and free fatty acids $(\sim 4.5 \%)$ [4]. RBO is also rich in compounds such as oryzanol and tocotrienes having antioxidant and cholesterol-reducing activities [5-8]. TAGs inRBO are

\footnotetext{
* Correspondence: sadequr.rahman@monash.edu

'School of Science, Monash University Malaysia, 46150 Bandar Sunway, Selangor, Malaysia

${ }^{2}$ Monash University Malaysia Genomics Facility, 46150 Bandar Sunway,

Selangor, Malaysia

Full list of author information is available at the end of the article
}

composed of three main fatty acids: palmitic acid, oleic acid and linoleic acid. The relative content of palmitic (15-20\%), oleic (36-48\%) and linoleic acids (30-38\%) depends on the cultivar and environment $[9,10]$.

Linoleic acid can undergo non-enzymatic oxidation because of the presence of the two reactive double bonds in the molecule $[11,12]$ which reduces the shelf-life of RBO and leads to wastage of $60-70 \%$ of RBO [6, 13]. Therefore, partial hydrogenation has often been used to enhance the oxidative stability of $\mathrm{RBO}$, resulting in nutritionally undesirable trans fatty acids as a by-product. Trans fatty acids have been found to increase the risk of cardiovascular diseases and have been prohibited in foods in an increasing number of countries in the world [14-17]. On the other hand, oleic acid is both oxidatively stable and nutritionally desirable, hence favored for direct food applications without partial hydrogenation. 
The microsomal enzyme $\Delta 12$ fatty acid desaturase (FAD2) converts oleic acid into linoleic acid while associated with phosphatidylcholine in the endoplasmic reticulum (ER). A total of 18 desaturase genes have been annotated in rice genome, among which are the four $F A D 2$ genes investigated by Zaplin et al. [18]. These were termed OsFAD2-1, $-2,-3$ and -4 . Among these four genes, the expression of OsFAD2-1 was reduced by RNA interference (RNAi) suppression which resulted in an increase in the proportion of oleic acid and a reduction of the proportions of linoleic and palmitic acids in $\mathrm{T}_{3}$ grains. Our previous results suggested that the OsFAD2-1gene was an effective target for raising oleic acid levels at the expense of the oxidatively unstable linoleic acid and the cholesterol-raising palmitic acid [18].

Most reports of genetic modification and characterisation of oil accumulation in plants have so far been carried out in Arabidopsis and classic dicot oilseed crops and focused mainly on trait development [19-24]. We have therefore decided to investigate further the role of the OsFAD2-1 gene in the rice grain. The comparative analysis of lipid fractions in wild type (WT) and HO-RBO was carried out. We also describe the use of Illumina-based NGS transcriptomic analysis on the same selected $\mathrm{HO}$ rice line to study the effect of RNAi down-regulation of OsFAD2-1 on the grain transcriptome, especially on other genes that are involved in lipid biosynthesis and turnover. Preliminary qPCR experiments confirmed the transcriptomic results for some of the selected genes. In this paper we also show that the down-regulation of OSFAD2-1with a seed-specific promoter to produce $\mathrm{HO}$ rice line was not associated with compromised oil accumulation in the grain, but rather a modest increase.

\section{Results and discussion}

Analysis of lipid composition in rice grains from $\mathrm{HO}$ rice line and its null segregant

Total lipids were analysed from the $\mathrm{HO}$ rice grains. These grains were from the homozygous transgenic line containing the OsFAD2-1 RNAi construct that was used for transcriptomics analysis. The total lipids in the $\mathrm{HO}$ rice grain were composed of $55.0 \%$ oleic acid, $19.8 \%$ linoleic acid and $16.8 \%$ palmitic acid, whereas the grains from a null segregant (a sister line derived from the same original transformation event that does not contain the OsFAD2-1 RNAi construct) comprised $32.3 \%$ oleic acid, $40.7 \%$ linoleic acid and $18.6 \%$ palmitic acid (Table 1 ). The oleic acid content from $\mathrm{HO}$ rice line was significantly higher than that from its null segregant $(p<0.05)$. Similar changes were also observed in TAG and phosphatidylcholine $(\mathrm{PC})$ pools, however, there were somewhat different fatty acid compositional profiles for polar lipids, such as the phosphatidylethanolamine (PE) and phosphatidylcholine (PC) pools. The overall results are in broad agreement with the results from Zaplin et al. [18] from an earlier generation of this material (Additional file 1).

Grains from OsFAD2-1 RNAi line contained higher levels of total lipids ( $2.9 \%$ by dry weight) compared to $2.6 \%$ in its null segregant $(p<0.05)$, which was reflected by the significant increases in both TAG and polar lipids.

\section{Transcriptome analysis of rice immature endosperms from $\mathrm{HO}$ rice line and its null segregant}

RNAseq reads from three developmental stages of endosperm of both the $\mathrm{HO}$ rice line and its null segregant were mapped against the reference rice genome (cultivar Nipponbare) [25] to generate the mapped contigs as

Table 1 Fatty acid composition of rice grains of OsFAD2-1 RNAi line and its null segregant line

\begin{tabular}{|c|c|c|c|c|c|c|c|c|c|c|c|c|}
\hline & \multicolumn{2}{|c|}{ Total lipids } & \multicolumn{2}{|c|}{ Triacylglycerols } & \multicolumn{2}{|c|}{ Polar lipid pool } & \multicolumn{2}{|c|}{ Free fatty acids } & \multicolumn{2}{|l|}{$P C$} & \multicolumn{2}{|l|}{ PE } \\
\hline & Control & Fad2 & Control & Fad2 & Control & Fad2 & Control & Fad2 & Control & Fad2 & Control & Fad2 \\
\hline $\mathrm{Cl} 4: 0$ & $0.6 \pm 0.0$ & $0.3 \pm 0.0$ & $0.5 \pm 0.0$ & $0.3 \pm 0.0$ & $2.5 \pm 0.1$ & $1.2 \pm 0.1$ & $1.6 \pm 0.0$ & $0.9 \pm 0.1$ & 1.1 & 0.6 & 1.6 & 1.2 \\
\hline $\mathrm{Cl} 6: 0$ & $18.6 \pm 0.2$ & $16.8 \pm 0.4$ & $18.4 \pm 0.1$ & $16.3 \pm 0.3$ & $26.7 \pm 1.0$ & $25.2 \pm 0.8$ & $18.7 \pm 0.6$ & $22.2 \pm 0.6$ & 21.0 & 17.8 & 25.8 & 24.1 \\
\hline Cl6:1 & $0.3 \pm 0.0$ & $0.3 \pm 0.0$ & $0.3 \pm 0.0$ & $0.3 \pm 0.0$ & $0.2 \pm 0.0$ & $0.3 \pm 0.0$ & $0.2 \pm 0.0$ & $0.3 \pm 0.0$ & 0.3 & 0.3 & 0.3 & 0.3 \\
\hline $\mathrm{Cl} 8.0$ & $2.4 \pm 0.0$ & $2.6 \pm 0.1$ & $2.4 \pm 0.1$ & $2.6 \pm 0.1$ & $1.8 \pm 0.1$ & $2.1 \pm 0.1$ & $3.0 \pm 0.1$ & $3.8 \pm 0.2$ & 1.5 & 1.4 & 2.2 & 19 \\
\hline 08.1 & $32.3 \pm 0.4$ & $55.0 \pm 0.7$ & $33.8 \pm 0.3$ & $56.2 \pm 0.7$ & $24.1 \pm 1.0$ & $43.9 \pm 14$ & $11.8 \pm 0.3$ & $45.4 \pm 0.9$ & 38.8 & 55.4 & 25.4 & 41.8 \\
\hline C18:Id11 & $1.0 \pm 0.0$ & $1.1 \pm 0.0$ & $1.0 \pm 0.0$ & $1.1 \pm 0.0$ & $1.1 \pm 0.0$ & $1.2 \pm 0.0$ & $0.6 \pm 00$ & $0.8 \pm 0.0$ & 1.4 & 1.4 & 1.3 & 1.3 \\
\hline $\mathrm{Cl} 8.2$ & $40.7 \pm 0.4$ & $19.8 \pm 0.7$ & $40.2 \pm 0.5$ & $19.8 \pm 0.6$ & $36.6 \pm 0.4$ & $20.0 \pm 0.6$ & $58.9 \pm 0.6$ & $21.4 \pm 1.3$ & 33.2 & 20.4 & 40.3 & 26.2 \\
\hline Cl8:3n3 & $1.7 \pm 0.1$ & $1.5 \pm 0.1$ & $1.7 \pm 0.1$ & $1.4 \pm 0.1$ & $1.5 \pm 0.2$ & $1.5 \pm 0.1$ & $2.5 \pm 0.0$ & $2.4 \pm 0.2$ & 1.4 & 1.2 & 1.3 & 1.1 \\
\hline C20:0 & $0.7 \pm 0.0$ & $0.8 \pm 0.0$ & $0.7 \pm 0.0$ & $0.8 \pm 0.0$ & $0.3 \pm 0.0$ & $0.3 \pm 0.0$ & $0.3 \pm 00$ & $0.4 \pm 0.0$ & 0.2 & 0.2 & 0.2 & 0.3 \\
\hline C20:1d11 & $0.4 \pm 0.0$ & 0.60 .0 & $0.4 \pm 0.0$ & $0.6 \pm 0.0$ & $0.1 \pm 0.0$ & $0.2 \pm 0.0$ & $0.1 \pm 0.1$ & $02 \pm 0.0$ & 0.2 & 0.2 & 0.1 & 0.2 \\
\hline C22:0 & $0.4 \pm 0.0$ & $0.4 \pm 0.0$ & $0.2 \pm 0.0$ & $0.2 \pm 0.0$ & $1.3 \pm 0.1$ & $1.1 \pm 0.1$ & $0.5 \pm 0.0$ & $0.5 \pm 0.0$ & 0.3 & 0.3 & 0.4 & 0.4 \\
\hline C24:0 & $0.8 \pm 0.0$ & $0.8 \pm 0.0$ & $0.4 \pm 0.0$ & $0.4 \pm 0.0$ & $3.7 \pm 0.3$ & $3.2 \pm 0.3$ & $1.9 \pm 0.1$ & $1.8 \pm 02$ & 0.7 & 0.7 & 1.2 & 1.3 \\
\hline$\%$ oil/wt & $2.6 \pm 0.1$ & $2.9 \pm 0.1$ & $1.8 \pm 0.1$ & $2.1 \pm 0.1$ & $0.21 \pm 0.01$ & $0.23 \pm 0.00$ & $0.07 \pm 0.00$ & $0.08 \pm 0.01$ & 0.06 & 0.08 & 0.02 & 0.02 \\
\hline
\end{tabular}

Control: represents grains from null segregant; Fad2: represents grains from OsFAD2-1RNAi line; numbers represent mean \pm SE in percentage (\%); Mean Values are from three repeat analyses of lipid samples which were extracted separately from three independent grain samples 
summarised in Table 2. In total, 1.5-9 million of contigs per sample were assembled which included approximately 80-94 \% counted contigs for use in further analysis, and 6-20\% un-counted contigs, defined as the total number of fragments after sequencing which could not be mapped, either as intact or as broken pairs. Among the counted contigs, $75-86 \%$ were unique, and 3$10 \%$ were non-specific contigs, defined as the reads which have multiple equally good alignments to the reference and therefore have to be excluded from the RNA-seq analysis.
The genes analysed could be grouped broadly into four categories: genes known to be involved in fatty acid biosynthesis and degradation, genes involved in TAG metabolism, transcriptional factors and other genes found to be affected (Additional file 2 and Additional file 3). A total of 55,801 different gene transcripts were detected in the overall analyses out of which 1,617 (2.9\%) genes at 10 days after anthesis (DAA), 1,175 (2.1\%) genes at 15 DAA and $626(1.12 \%)$ genes at 20 DAA showed significant differences in expression between the null segregant and the $\mathrm{HO}$ rice line.

Table 2 Mapped contig results of RNA-Seq reads from null segregant (NG) and OsFAD2-1RNAi rice lines at three grain developmental stages

\begin{tabular}{|c|c|c|c|c|c|c|}
\hline \multirow[t]{2}{*}{ Contigs } & \multicolumn{3}{|c|}{ Null segregant } & \multicolumn{3}{|c|}{ Os-FAD2-1 RNAi } \\
\hline & Sample1 & Sample 2 & Sample 3 & Sample 1 & Sample 2 & Sample 3 \\
\hline \multicolumn{7}{|l|}{10 DAA } \\
\hline Counted contigs & $1,474,350$ & $2,451,049$ & 912,841 & $2,305,750$ & $7,974,195$ & $3,179,294$ \\
\hline Unique contigs & $1,403,705$ & $2,334,799$ & 858,280 & $2,090,665$ & $7,406,550$ & $3,050,886$ \\
\hline Non-S contigs & 70,645 & 116,250 & 54,561 & 215,085 & 567,645 & 128,408 \\
\hline Un-C contigs & 380,469 & 691,998 & 678,922 & 221,969 & $1,119,121$ & 590,977 \\
\hline Total contigs & $1,854,819$ & $3,143,047$ & $1,591,763$ & $2,527,719$ & $9,093,316$ & $3,770,271$ \\
\hline Counted contigs (\%) & 79.49 & 77.98 & 57.35 & 91.22 & 87.69 & 84.33 \\
\hline Unique contigs (\%) & 75.68 & 74.28 & 53.92 & 82.71 & 81.45 & 80.92 \\
\hline Non-S contigs (\%) & 3.81 & 3.70 & 3.43 & 8.51 & 6.24 & 3.41 \\
\hline Un-C contigs (\%) & 20.51 & 22.02 & 42.65 & 8.78 & 12.31 & 15.67 \\
\hline \multicolumn{7}{|l|}{15 DAA } \\
\hline Counted contigs & $1,721,045$ & $4,038,637$ & $6,507,485$ & $1,260,698$ & $4,102,787$ & $5,184,375$ \\
\hline Unique contigs & $1,580,034$ & $3,759,033$ & $5,944,747$ & $1,211,621$ & $3,877,771$ & $4,889,384$ \\
\hline Non-S contigs & 141,011 & 279,604 & 562,738 & 49,077 & 225,016 & 294,991 \\
\hline Un-C contigs & 210,716 & 347,568 & 496,403 & 385,614 & $1,123,069$ & 436,145 \\
\hline Total contigs & $1,931,761$ & $4,386,205$ & $7,003,888$ & $1,646,312$ & $5,225,856$ & $5,620,520$ \\
\hline Counted contigs (\%) & 89.09 & 92.08 & 92.91 & 76.58 & 78.51 & 92.24 \\
\hline Unique contigs (\%) & 81.79 & 85.70 & 84.88 & 73.60 & 74.20 & 86.99 \\
\hline Non-S contigs (\%) & 7.30 & 6.37 & 8.03 & 2.98 & 4.31 & 5.25 \\
\hline Un-C contigs (\%) & 10.91 & 7.92 & 7.09 & 23.42 & 21.49 & 7.76 \\
\hline \multicolumn{7}{|l|}{20 DAA } \\
\hline Counted contigs & $2,945,375$ & $1,943,916$ & $1,348,074$ & $3,914,475$ & 791,645 & $3,627,328$ \\
\hline Unique contigs & $2,797,599$ & $1,778,024$ & $1,212,290$ & $3,446,816$ & 734,727 & $3,386,969$ \\
\hline Non-S contigs & 147,776 & 165,892 & 135,784 & 467,659 & 56,918 & 240,359 \\
\hline Un-C contigs & 447,772 & 250,284 & 168,761 & 441,185 & 464,829 & 492,027 \\
\hline Total contigs & $3,393,097$ & $2,194,200$ & $1,516,835$ & $4,355,660$ & $1,256,474$ & $4,119,355$ \\
\hline Counted contigs (\%) & 89.09 & 88.59 & 88.87 & 89.87 & 63.01 & 88.06 \\
\hline Unique contigs (\%) & 86.80 & 81.03 & 79.92 & 79.13 & 58.48 & 82.22 \\
\hline Non-S contigs (\%) & 82.45 & 7.56 & 8.95 & 10.74 & 4.53 & 5.83 \\
\hline Un-C contigs (\%) & 4.36 & 11.41 & 11.13 & 10.13 & 36.99 & 11.94 \\
\hline
\end{tabular}

Non-S contigs- Non-specific contigs; Un C contigs-Un-counted contigs 


\section{Expression of genes involved in fatty acid biosynthesis and degradation}

De novo fatty acid biosynthesis occurs primarily in plastids, although it also occurs in the mitochondrion to a much lesser extent $[26,27]$. The first addition of a malonyl group to an acetyl group is catalysed by KASIII, while the subsequent acyl chain elongation up to $\mathrm{C} 16$ and the final two-carbon extension to form C18 fatty acid while associated with acyl carrier protein (ACP) are catalysed by KASI and KASII, respectively (Additional file 4: Table S1). None of the putative transcripts for $K A S$ genes were affected by the RNAi down-regulation of OsFAD2-1 gene (LOC_Os02g48560) (Additional file 5).

Termination of fatty acid elongation in plastids is catalysed by acyl-ACP thioesterase enzymes (Fat), 25 unigenes of which have been annotated in the Rice Genome project [25]. Among them FatA and FatB are represented by LOC_Os09g32760 and LOC_Os06g05130, respectively. FatA preferentially catalyses the cleavage of the thioester bond of oleyl-ACP, and is also regarded as one of the key enzymes responsible for oleic acid concentration in oil and FatB has substrate preference forC16 - C18 saturated fatty acids [28]. Expression of FatA was found significantly reduced at 15 DAA by -1.62 fold $(p=0.04)$ equivalent to $-0.91 \log 2$ fold (Table 3 ). This is in contrast to the transcript abundance of $F a t B$ that was not affected in the RNAi-OsFAD2-1line, compared to the null segregant control, in all three developmental stages analysed (Fig. 1a). Significant differences in the expression levels of FatA and FatB were not observed at 10 and 20 DAA.

The first desaturation step of a saturated fatty acid occurs in the plastids, catalysed by stearoyl-ACP desaturase (SAD). SAD is a soluble plastidial enzyme that introduces the first double bond into stearic acid and to a lesser extent palmitic acid to form oleic acid and palmitoleic acid, respectively. LOC_Os01g69080annotated as SAD2gene was highly expressed in rice grains at 10 DAA. In comparison to the null segregant, the expression level of SAD2 was reduced by -1.6 and -1.35 fold in the $\mathrm{HO}$ rice grains at 15 DAA $(p=0.02)$ and 20 DAA $(p=0.01)$ respectively, while no significant difference was observed at 10 DAA (Table 3, Fig. 1a). SAD5 (LOC_Os04g31070) expression was also found to be down regulated at 15 DAA by -1.88 fold $(p=2.17 \mathrm{E}-4)$ and $-1.12 \log 2$ fold change (Table 3, Fig. 1a). No significant change in expression was found in other unigenes annotated for encoding $\mathrm{SAD}$ in the $\mathrm{HO}$ line compared to null segregant (Additional file 2).

The nucleotide sequence alignment match between either of $S A D 2$ or $S A D 5$ and OSFAD2-1 is generally low and stretches of 20 nucleotide DNA sequences with significant identity were not found. It is therefore unlikely that the decrease in expression level of $S A D$ genes in $\mathrm{HO}$ line was due to cross silencing. As SAD is an upstream fatty acid desaturase of FAD2, it is tempting to assume that the reduction in the expression of OsFAD2-1 leading to the build-up of oleic acid may have a feedback effect that leads to the down regulation of SAD expression which is responsible for oleic acid production.

Oleic acid could be further modified by FAD2 in endoplasmic reticulum (ER) through the eukaryotic pathway or by FAD6 in plastids via the prokaryotic pathway. In the previous study [18], four genes in the rice genome were putatively identified as FAD2 that are present in the eukaryotic pathway, LOC_Os02g48560 (OsFAD2-1), LOC_Os07g23430 (OsFAD2-2), LOC_Os07g23410 (Os FAD2-3) and LOC_Os07g23390 (OsFAD2-4). Transcriptome analysis showed that the expression patterns of all the four OSFAD2 genes were consistent with the previous data of Zaplin et al. [18] and the analysis of publicly available transcriptome data (Additional file 6: Table S2). The analysis of transcriptome data described in this paper showed that, only OsFAD2-1 transcripts were found in all three grain developmental stages (10, 15 and 20 DAA) (Table 4). The highest expression level of OsFAD2-1 was found in the early developmental stage in the null segregant line and it declined as the grains developed. Such a finding is consistent with Wang et al. [29] who found that in sesame most of the genes related to lipid biosynthesis were highly expressed at early stage of seed development, which is at 10 DAA. This may suggest that the biosynthesis of polyunsaturated fatty acids is initiated at a rather early stage of grain development. Such a factor needs to be considered for the choice of promoter that drives the hairpin expression cassette of the OsFAD21 sequence in RNAi construct. The HO rice line was generated by using a storage protein promoter, Bx17, which becomes most active from the mid-stage of endosperm development onwards [18]. It is tempting to assume that further enhancement of oleic acid accumulation above that observed in the current transgenic lines is possible when an alternative grain- or bran- specific promoter that is active from early grain development is employed.

The expression of OsFAD2-1 in the $\mathrm{HO}$ rice lines was significantly down regulated in all the three developmental stages examined, with the most marked reduction by -2.05 fold $(p=9.15 \mathrm{E}-6)$ and $-1.22 \log 2$ fold at 15 DAA (Table 3, Fig. 1a). This is anticipated because OsFAD21was specifically targeted by RNAi mediated gene silencing. However, the down-regulation of OsFAD2-1 expression did not result in detectable level of alteration in the already very low expression of OsFAD2-2, -3, -4 genes at 10, 15 and 20 DAA stages.

Effect on long chain fatty acyl-CoA synthetases (LACS) genes Long chain fatty acyl-CoA synthetases (LACS) are known to be involved in the breakdown of complex fatty acids. Among a total of five annotated LACS unigenes in rice, LOC_Os05g25310 was found to be significantly 
Table 3 Differential expression of genes in the metabolism of Fatty acid and TAG biosynthesis

\begin{tabular}{|c|c|c|c|c|c|c|}
\hline Feature ID & Gene abbreviation & DAA & $\begin{array}{l}\text { Weighted proportions } \\
\text { fold change }\end{array}$ & $P$-value & $\begin{array}{l}\text { RNAi/WT mean } \\
\text { fold change }\end{array}$ & $\begin{array}{l}\text { RNAi/WT mean log2 } \\
\text { fold change }\end{array}$ \\
\hline LOC_Os09g32760 & FATA & 10 & -1.1 & 0.54 & 0.93 & -0.11 \\
\hline LOC_Os09g32760 & FATA & 15 & -1.62 & ${ }^{*} 0.04$ & 0.53 & -0.91 \\
\hline LOC_Os09g32760 & FATA & 20 & -1.28 & 0.22 & 0.80 & -0.32 \\
\hline LOC_Os01g69080 & SAD2 & 10 & -1.04 & 0.76 & 0.98 & -0.03 \\
\hline LOC_Os01g69080 & SAD2 & 15 & -1.57 & ${ }^{*} 0.02$ & 0.55 & -0.85 \\
\hline LOC_Os01g69080 & SAD2 & 20 & -1.35 & ${ }^{*} 0.01$ & 0.75 & -0.41 \\
\hline LOC_Os04g31070 & SAD5 & 10 & -1.31 & 0.2 & 0.78 & -0.37 \\
\hline LOC_Os04g31070 & SAD5 & 15 & -1.88 & $* 2.17 \mathrm{E}-4$ & 0.46 & -1.12 \\
\hline LOC_Os04g31070 & SAD5 & 20 & -1.01 & 0.92 & 1.01 & 0.01 \\
\hline LOC_Os05g25310 & LACS & 10 & -1.3 & 0.13 & 0.78 & -0.36 \\
\hline LOC_Os05g25310 & LACS & 15 & -1.45 & ${ }^{*} 0.04$ & 0.59 & -0.76 \\
\hline LOC_Os05g25310 & LACS & 20 & -1.37 & 0.23 & 0.74 & -0.43 \\
\hline LOC_Os01g70090 & $\mathrm{ECH} 1$ & 10 & -1.11 & 0.56 & 0.91 & -0.13 \\
\hline LOC_Os01g70090 & $\mathrm{ECH} 1$ & 15 & -1.64 & ${ }^{\mathrm{a}} 0.03$ & 0.53 & -0.93 \\
\hline LOC_Os01g70090 & $\mathrm{ECH} 1$ & 20 & 1.06 & 0.79 & 1.11 & 0.15 \\
\hline LOC_Os02g48560 & FAD2 & 10 & -2.1 & $* 2.02 \mathrm{E}-3$ & 0.48 & -1.05 \\
\hline LOC_Os02g48560 & FAD2 & 15 & -2.05 & *9.15E-6 & 0.43 & -1.22 \\
\hline LOC_Os02g48560 & FAD2 & 20 & -1.77 & ${ }^{*} 0.04$ & 0.59 & -0.75 \\
\hline LOC_Os06g22080 & DGAT2 & 10 & -1.31 & 0.45 & 0.76 & -0.39 \\
\hline LOC_Os06g22080 & DGAT2 & 15 & -1.71 & $* 7.73 \mathrm{E}-3$ & 0.51 & -0.98 \\
\hline LOC_Os06g22080 & DGAT2 & 20 & -1.16 & 0.28 & 0.89 & -0.17 \\
\hline LOC_Os02g50174 & Caleosin & 10 & 1.52 & 0.27 & 1.56 & 0.64 \\
\hline LOC_Os02g50174 & Caleosin & 15 & -1.33 & ${ }^{*} 0.04$ & 0.65 & -0.63 \\
\hline LOC_Os02g50174 & Caleosin & 20 & -1.97 & $* 5.02 \mathrm{E}-3$ & 0.51 & -0.97 \\
\hline LOC_Os03g12230 & Caleosin & 10 & -1.14 & 0.42 & 0.88 & -0.18 \\
\hline LOC_Os03g12230 & Caleosin & 15 & -1.58 & *6.60E-3 & 0.55 & -0.86 \\
\hline LOC_Os03g12230 & Caleosin & 20 & -1.27 & 0.5 & 0.81 & -0.31 \\
\hline LOC_Os04g32080 & STEROLEOSIN & 10 & -1.36 & 0.42 & 0.73 & -0.45 \\
\hline LOC_Os04g32080 & STEROLEOSIN & 15 & -1.36 & ${ }^{*} 0.03$ & 0.64 & -0.65 \\
\hline LOC_Os06g22080 & STEROLEOSIN & 20 & -1.16 & 0.28 & 0.89 & -0.17 \\
\hline LOC_Os02g49410 & LEC1 & 10 & -1.23 & 0.42 & 0.81 & -0.30 \\
\hline LOC_Os02g49410 & LEC1 & 15 & -1.66 & *3.91E-3 & 0.53 & -0.92 \\
\hline LOC_Os02g49410 & LEC1 & 20 & -1.44 & 0.12 & 0.71 & -0.49 \\
\hline
\end{tabular}

*represents significant $p$-values

down regulated by -1.45 fold $(p=0.04)$ and $-0.76 \log 2$ fold in the HO line at 15 DAA (Table 3, Fig. 1a) compared to the null segregant. Such reduction of LOC_Os05g25310 was also verified by real time quantitative reverse transcriptase polymerase chain reaction (qRT-PCR) (Fig. 2) indicating the significant reduction of the expression at 15 DAA developmental stage. The significance of such a down-regulation remains unclear. There was no significant change in the expression of LOC_Os05g25310 at 10 and 20 DAA. Expression of LOC_Os05g25310 was the highest at 10 DAA with a gradual decrease as the rice grain development progressed.

\section{Effects on TAG assembly}

As the major storage lipid in oilseeds, TAG is utilized to fuel seed germination and early seedling establishment prior to autotrophy by photosynthesis [30, 31]. Given the potential importance of the $\mathrm{HO}$ trait in rice bran oil, it is pivotal to understand whether and how the TAG biosynthesis, turnover and catabolism are impacted upon in the $\mathrm{HO}$ grains. 


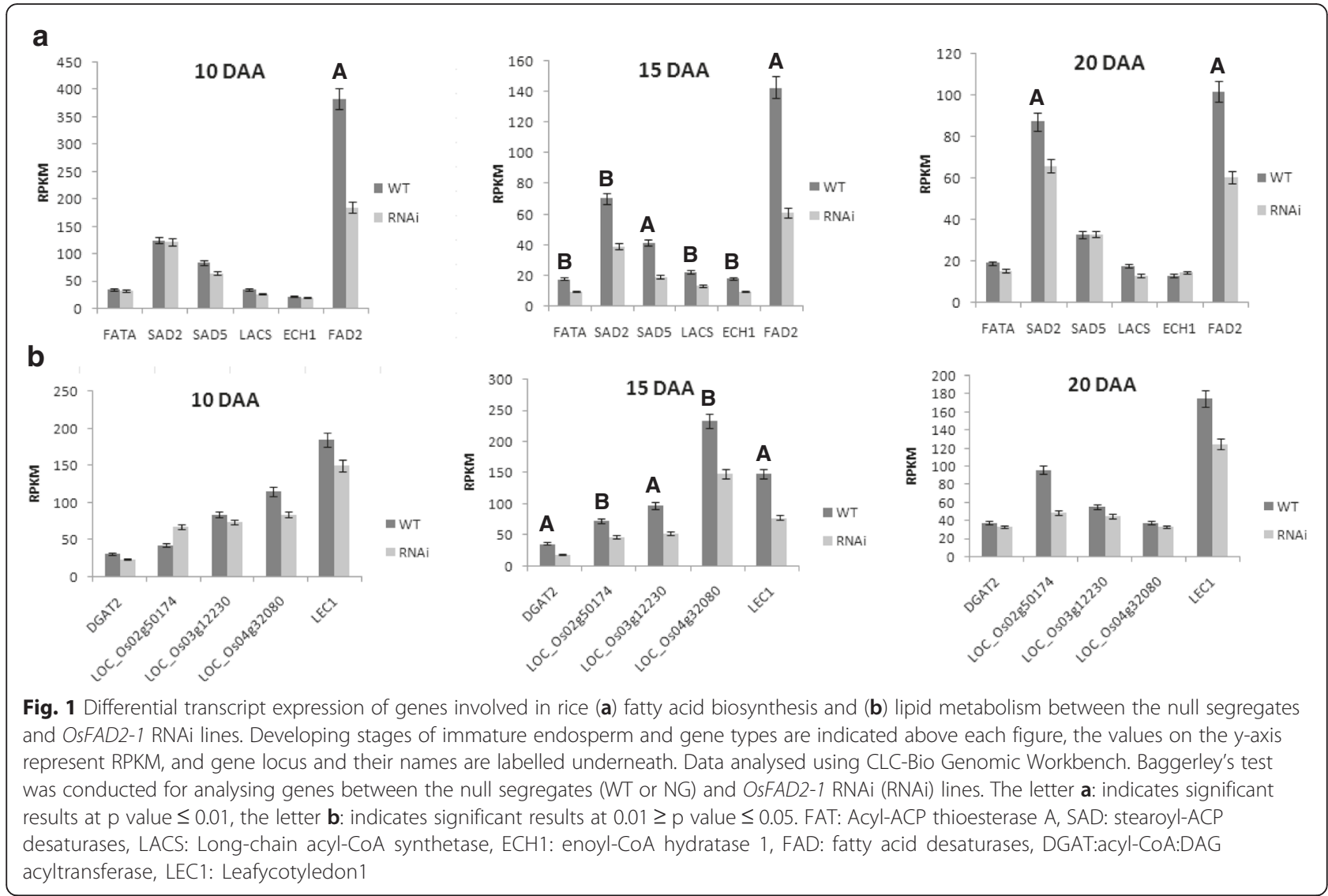

TAG biosynthesis starts with glycerol-3-phosphate (G3P). Apart from glycolysis, G3P could also be produced by the action of glycerol kinase (GK). There are 14 unigenes encoding for $\mathrm{GK}$ as annotated in the rice genome database [25]. None of the $G K$ genes was affected in their expression in any of the time points in the $\mathrm{HO}$ rice line. Also, there was no effect on the expression of the 18 annotated genes encoding for GPAT required to form lysophosphatidic acid (LPA) at the next stage of TAG assembly.

LPA is acylated by a lysophosphatidic acid acyltransferase (LPAAT) enzyme to form phosphatidic acid (PA). Again the expression of annotated LPAAT genes (http:// rice.plantbiology.msu.edu/) was not affected in the $\mathrm{HO}$ rice. Diacylglycerol (DAG) is generated by removing the phosphate group from PA by phosphatidic acid phosphohydrolase (PAP). PAP1 (LOC_Os01g63060), PAP2 (LOC_Os05g21180) and PAP3 (LOC_Os05g37910) have been annotated in the rice genome database [25]. TAG can be synthesised from DAG in two ways, the acyl-CoA dependent which is normally known as the Kennedy pathway or the acyl-CoA independent pathway. DGAT catalyses the last step of Kennedy pathway by transferring an acyl group from acyl-CoA to DAG to generate de novo TAG and has been implicated as the key enzyme in determining the oil content in seed oil [32, 33]. Expression of DGAT2 (LOC_Os06g22080) was found to increase with the seed development in the null segregant. At 15 DAA, expression of DGAT2 was significantly down regulated by -1.71 fold $(p=7.73 \mathrm{E}-3)$ and -0.98 $\log 2$ fold (Table 3 ) in the HO line. There was no significant difference in the expression level of DGAT2 gene at other time points between $\mathrm{HO}$ and the null segregant line (Table 3, Fig. 1b). DGAT2 has been regarded as a key enzyme in incorporation of unusual fatty acids such as epoxy or hydroxyl fatty acids in TAG to prevent their accumulation in the form of free fatty acids which might cause membrane dysfunction [34, 35]. The other DGAT enzyme, DGAT1, has low expression in the endosperm and no effect was detected.

The acyl-CoA independent reactions are involved in the conversion of two DAGs into a monoacyl glycerol (MAG) and a TAG by DAG:DAG transacylase $[36,37]$ or the conversion of DAG to TAG by an acyl transfer from the sn-2 position of PC to DAG by Phospholipid:diacylglycerolacyltransferase (PDAT) using PC as acyl donor in TAG formation [34, 38]. In the null segregant, among the 8 annotated PDAT unigenes, the majority of them were found to express at high levels at 10 DAA and decrease in expression in mature grains. Such an expression pattern 
Table 4 Expressionlevels of four FAD2 genes in a null segregant (NG) and an OsFAD2-1RNAi line at 10, 15 and 20 DAA developmental stages

\begin{tabular}{|c|c|c|c|c|c|c|c|c|c|c|}
\hline DAA & Gene & $\begin{array}{l}\text { Rice Genome } \\
\text { Annotation } \\
\text { Project locus ID }\end{array}$ & $\begin{array}{l}\text { NG } 1 \\
\text { (RPKM) }\end{array}$ & $\begin{array}{l}\text { NG2 } \\
\text { (RPKM) }\end{array}$ & $\begin{array}{l}\text { NG3 } \\
\text { (RPKM) }\end{array}$ & $\begin{array}{l}\text { NG } \\
\text { (RPKM mean) }\end{array}$ & $\begin{array}{l}\text { OsFAD2-1RNAi } 1 \\
\text { (RPKM) }\end{array}$ & $\begin{array}{l}\text { OsFAD2-1RNAi } 2 \\
\text { (RPKM) }\end{array}$ & $\begin{array}{l}\text { OsFAD2-1 RNAi } 3 \\
\text { (RPKM) }\end{array}$ & $\begin{array}{l}\text { OsFAD2-1RNAi } \\
\text { (RPKM mean) }\end{array}$ \\
\hline 10 & OsFAD2-1 & LOC_Os02g48560 & 296.6 & 371.57 & 482.81 & 383.66 & 188.21 & 210.85 & 158.01 & 185.69 \\
\hline 15 & OsFAD2-1 & LOC_Os02g48560 & 134.18 & 133.69 & 160.53 & 142.8 & 34.8 & 89.31 & 59.16 & 61.09 \\
\hline 20 & OsFAD2-1 & LOC_Os02g48560 & 89.67 & 89.96 & 128.16 & 101.93 & 54.63 & 55.79 & 70.9 & 60.44 \\
\hline 10 & OsFAD2-2 & LOC_Os07g23430 & 0 & 0 & 0 & 0 & 0 & 0 & 0 & 0 \\
\hline 15 & OsFAD2-2 & LOC_Os07g23430 & 0 & 0 & 0 & 0 & 0 & 0 & 0 & 0 \\
\hline 20 & OsFAD2-2 & LOC_Os07g23430 & 0 & 0 & 0 & 0 & 0.13 & 0 & 1.3 & 0.48 \\
\hline 10 & OsFAD2-3 & LOC_Os07g23410 & 0 & 0 & 0.15 & 0.53 & 0.15 & 0.5 & 0 & 0.23 \\
\hline 15 & OsFAD2-3 & LOC_Os07g23410 & 0.19 & 0.06 & 0 & 0 & 0 & 0 & 0 & 0 \\
\hline 20 & OsFAD2-3 & LOC_Os07g23410 & 0.46 & 0.15 & 0.31 & 0 & 0.31 & 0 & 0 & 0.10 \\
\hline 10 & OsFAD2-4 & LOC_Os07g23390 & 0 & 0 & 0 & 0 & 0 & 0 & 0 & 0 \\
\hline 15 & OsFAD2-4 & LOC_Os07g23390 & 0 & 0.22 & 0 & 0.07 & 1.18 & 0.36 & 0 & 0.51 \\
\hline 20 & OsFAD2-4 & LOC_Os07g23390 & 0 & 0 & 0 & 0 & 0 & 0.82 & 1.87 & 0.90 \\
\hline
\end{tabular}

DAA-days after anthesis 

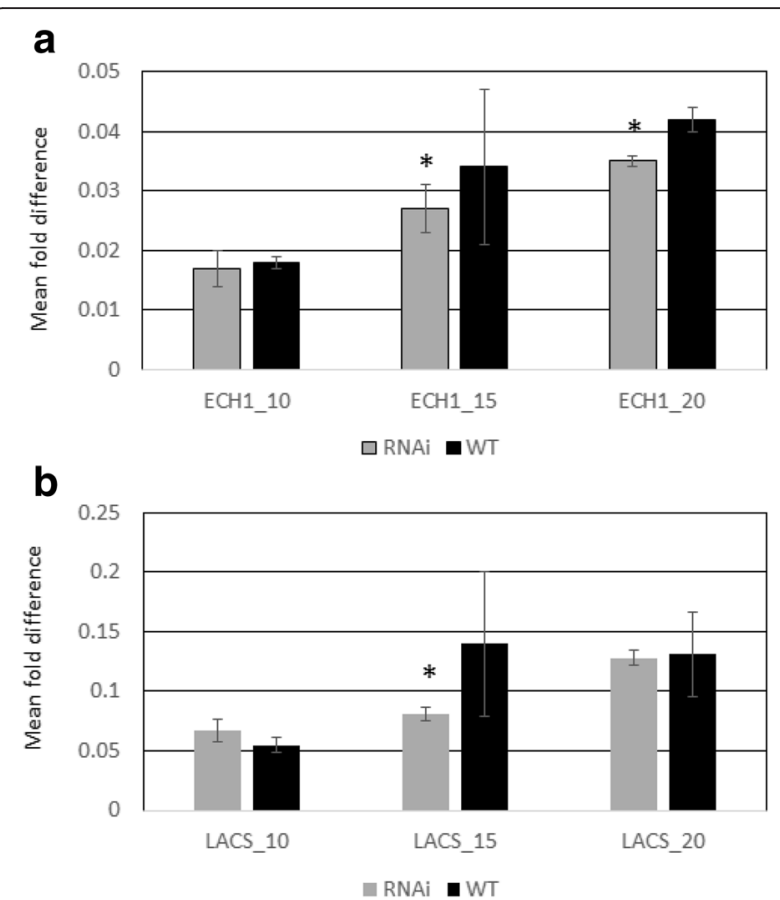

Fig. 2 Level of ECH1 and LACS transcripts of two OsFAD2-1 RNAi lines (RNAi) and two null segregants (WT) at three different developmental stages. The $\triangle \triangle C T$ method [55] was used to determine the expression of the ECH1 (a) and LACS (b) gene transcripts normalised to the a-tubulin housekeeping gene from qRT-PCR data to produce a mean fold difference. Error bars are one standard error (s.e). ECH1_10: ECH1 gene at 10 DPA; ECH1_15: ECH1 gene at 15DAA; ECH1_20: ECH1 gene at 20 DAA; LACS_10: LACS gene at 10 DAA; LACS_15: LACS gene at 15 DAA; LACS_20: LACS gene at 20 DAA; OsFAD2-1RNAi Line 22-4 (4) and Line 22-4 (5) were used as transgenic lines, OsFAD2-1 RNAi Line 22-4 (1) and Line 22-4 (2) were used as the null segregants. All four lines were derived from one OsFAD2-1 RNAi 22-4 $\mathrm{T}_{2}$ plant.* shows the significantly different at $P<0.05$ levels

was not affected in the HO line. The PDAT route is a mechanism for incorporation of unusual fatty acids in Ricinus communis by their direct transfer from PC to DAG [39, 40]. As unusual fatty acids have not been reported in rice bran oil, the significance of PDAT in RBO biosynthesis remains unresolved. The consistent expression between WT and $\mathrm{HO}$ rice may indicate the PDAT is not a key enzyme determining the oleic acid accumulation in RBO.

\section{Effect on genes involved in TAG packaging and oil body formation}

TAG molecules synthesised are packaged and stored in oil bodies (OBs). OBs are maintained and protected by a single layer of $\mathrm{PC}$ and proteins which include oleosins, caleosins and steroleosins, with oleosin being the most abundant [41, 42]. Six oleosin genes, 9 caleosin genes and 1 steroleosin gene have been annotated in the rice genome database [25]. Our transcriptomics data showed that in the null segregant each of the three classes of oil body protein genes is expressed in all the three developmental stages examined, and increased as the grain developed. The expression of the oleosins was not found to be significantly affected in the $\mathrm{HO}$ line when compared to null segregant rice grain.

Caleosins are calcium- binding $\mathrm{OB}$ proteins. The expression of caleosins is reduced during germination to provide access to lipases for breakdown of TAG [53]. Among caleosins, the expression of LOC_Os02g50174 in the $\mathrm{HO}$ rice was significantly down regulated at both 15 and 20 DAA by -1.33 (and $-0.63 \log 2$ fold) and -1.97 fold $(p=0.04,5.02 \mathrm{E}-3)(-0.97 \log 2$ fold)respectively; (Table 3 , Fig. 1b). Steroleosin has sterol-binding capacity and is mostly involved in signal transduction. The steroleosin unigene annotated as LOC_Os04g32080 was down regulated at 15 DAA by -1.36 fold $(p=0.03)$ and -0.65 $\log 2$ fold in the $\mathrm{HO}$ rice line (Table 3, Fig. 1b). It remains unclear how the down-regulation of OsFAD2-1 in rice led to the down-regulation of $\mathrm{OB}$ protein gene expression. It is also of particular interest that such a change did not result in the reduction, but rather a modest increase of oil accumulation in $\mathrm{HO}$ rice.

\section{Effects on genes involved in fatty acid and lipid catabolism} The key genes coding for the enzymes involved in $\beta$ oxidation or fatty acid catabolism were also analysed. In general, all enoyl-CoA hydratase $(\mathrm{ECH}), 3$ - hydroxyacylCoA dehydrogenase (HACDH), ketoacyl-CoA thiolase (KAT) and acyl-CoA thioesterase (ACT) genes were expressed at high levels at 10 DAA and their expression level gradually decreased as seed development progressed. In the $\mathrm{HO}$ line, at 15 DAA stage the expression of ECH1 (LOC_Os01g70090) was significantly reduced by -1.64 fold $(p=0.03)$ and $-0.93 \log 2$ fold, compared to the null segregant (Table 3, Fig. 1a). Such reduction of the expression was also supported by qRT-PCR analysis (Fig. 2).

In the $\mathrm{HO}$ line, the majority of lipases are found to be expressed at high levels in the early developmental stage at 10 DAA and gradually decreased at later stages. Down-regulation of lipase promotes TAG stabilisation in rice [43]. Among all four phospholipases (PLC1-4), PLC2 was found to be highly expressed with maximum expression at 10 DAA in null segregant. There was no significant variation on the PLC gene expression between the $\mathrm{HO}$ and null segregant.

\section{Expression of transcription factors that may be relevant to lipid accumulation}

Apart from the genes that encode functional enzymes or proteins in the lipid biosynthesis or catabolism pathways, several transcription factors such as Leafy cotyledon1 (LEC1), LEC2 and FUSCA3 Like 1 (FL1), Wrinkled 1 (WRI1) and Abscisic acid-insensitive (ABI3) are also known to regulate fatty acid and TAG biosynthesis and 
play an important role in lipid accumulation in seed, in addition to their roles in seed development and maturation [44-49]. At 15 DAA, the expression level of the unigene LOC_Os02g49410 annotated as LEC1 was significantly reduced by -1.66 fold $(p=3.91 \mathrm{E}-3)$ and -0.92 $\log 2$ fold in the $\mathrm{HO}$ line compared to the null segregant (Table 3, Additional file 5).

\section{Impact of OsFAD2-1 RNAi down regulation on other genes}

It was found that the expression of several genes not discussed above was also affected in the HO rice. These are not known to have a direct association with fatty acid and lipid biosynthesis (Additional file 7: Figure S1). For example, the expression of different storage protein genes were differentially regulated at all three stages in the $\mathrm{HO}$ rice grains (see Table 5). The expression patterns of additional selected genes being significantly affected in all the time points are also shown in Table 5. This data may facilitate the exploration of other potential molecular networks OsFAD2-1 might be involved, in addition to its key role in linoleic acid biosynthesis.

\section{Conclusion}

The transcriptomic analysis of the $\mathrm{HO}$ rice grains generated through RNAi down-regulation of OsFAD2-1 suggests that a suite of key genes involved in fatty acid biosynthesis, TAG assembly and turnover have been differentially regulated in order to incorporate the increased level of oleic acid in TAG that is stored in the form of OBs. Further, the observation of a modest increase in TAG in the $\mathrm{HO}$ rice grains may also suggest that the availability of high level of oleic acid is likely favourable for TAG biosynthesis in rice. Overall, this study has delineated a subset of lipid-metabolism genes as being affected when OsFAD2-1 is down-regulated and the proportion of oleic acid increases in TAG (Fig. 3). The impact on these genes is currently being verified by other techniques. It is envisaged that the genetic manipulation or co-expression of the genes clearly shown to be affected might lead to in further enhancement of the nutritionally desirable oleic acid and TAG accumulation in rice grains.

\section{Methods}

\section{Plant materials}

High oleic ( $\mathrm{HO}$ ) and null segregant rice (O. sativacv. Nipponbare) seeds were harvested in CSIRO Agriculture, Australia where the $\mathrm{HO}$ rice line was previously developed [18]. One OsFAD2-1RNAi silencing line, FAD2RNAi-22(4) and a null segregant, FAD2RNAi-22(8) were used for this study. These were derived from the progeny from one single transformation event, FAD2RNAi-22, which had a dramatic reduction of the targeted gene expression and high level of oleic acid content [18]. Rice plants were grown in a containment glasshouse with a constant temperature regime of $27{ }^{\circ} \mathrm{C}$ (day and night) under natural light. Fifteen to twenty of immature seeds were collected at 10, 15 and 20 DAA respectively. The endosperms were isolated from the developing grains, frozen in liquid nitrogen and preserved at $-80{ }^{\circ} \mathrm{C}$ freezer for RNA isolation. $\mathrm{T}_{5}$ seeds from $\mathrm{T}_{4}$ plants were analysed, whereas in Zaplin et al. [18], $\mathrm{T}_{4}$ seeds from $\mathrm{T}_{3}$ plants were analysed.

\section{Rice grain lipid analysis}

Mature brown rice grains were obtained by manual dehulling and ground with a CapMixTM capsule mixing device (3 M ESPE, Seefeld, Germany). Total lipids from $\sim 300 \mathrm{mg}$ above prepared rice flour samples were extracted with a mixture of chloroform/methanol/0.1 M $\mathrm{KCl}$ (at a ratio of $2 / 1 / 1$, by volume). Fatty acid methyl esters (FAME) were prepared by incubating lipid samples in $1 \mathrm{~N}$ Methanolic-HCl (Supelco, Bellefonte, PA) at $80{ }^{\circ} \mathrm{C}$ for $2 \mathrm{~h}$. TAG and polar membrane lipid pools were fractionated from total lipids in thin layer chromatography (TLC) (Silica gel 60, Merck, Darmstadt, Germany) using a solvent mixture of hexane/diethylether/acetic acid (at a ratio of $70 / 30 / 1$, by volume) and individual membrane lipid classes were separated by TLC using a solvent mixture of chloroform/methanol/acetic acid/ water ( $90 / 15 / 10 / 3$, by volume). Authentic lipid standards were loaded and were run in separate lanes on the same plates for identification of lipid classes. Silica bands, containing individual class of lipid were used to prepare FAME as mentioned above and were analysed by gas chromatography GC-FID 7890A (Agilent Technologies, Palo Alto, CA) that was fitted with a $30 \mathrm{~m}$ BPX70 column (SGE, Austin, TX) for quantifying individual fatty acids on the basis of peak area of the known amount of heptadecanoin that was added in as an internal standard [50].

\section{RNA isolation and transcriptomic analysis}

Total RNA was isolated from endosperm at 10, 15 and 20 DAA following the method of Higgins et al. [51] with modifications. For each RNA preparation, three endosperms were first ground in liquid nitrogen, then further ground with $600 \mu \mathrm{L}$ NTES buffer (containing 100 $\mathrm{mMNaCl}, 10 \mathrm{mMTris}$, pH8.0, 1 mM EDTA and $1 \%$ SDS), $800 \mu \mathrm{L}$ phenol/chloroform (Sigma-Aldrich, St. Louis, MO). Samples were transferred into Eppendorf tubes and centrifuged at 13,000x rpm for $5 \mathrm{~min}$ in a microcentrifuge. After transferring into new Eppendorf tubes, the supernatant was mixed with an equal volume of $4 \mathrm{M} \mathrm{LiCl} / 10 \mathrm{mM}$ EDTA solution and kept at $-20{ }^{\circ} \mathrm{C}$ overnight for RNA precipitation. RNA samples were precipitated by centrifugation at 10,000x rpm for $15 \mathrm{~min}$ at room temperature $\left(25{ }^{\circ} \mathrm{C}\right)$, rinsed with $70 \%$ ethanol and air dried. RNA pellets were dissolved in $360 \mu \mathrm{L}$ milliQ $\mathrm{H}_{2} \mathrm{O}$ and $40 \mu \mathrm{L}$ of $2 \mathrm{M} \mathrm{NaOAc}$, $\mathrm{pH} 5.8$, which were then precipitated again with $1 \mathrm{~mL} 95 \%$ 
Table 5 Differential expression of non lipid genes between OsFAD2-1RNAi lines and their null segregant (NG)

\begin{tabular}{|c|c|c|c|c|c|c|c|c|c|c|c|c|c|}
\hline \multirow[t]{2}{*}{ Gene ID } & \multirow[t]{2}{*}{ Gene description } & \multicolumn{2}{|c|}{10 DAA (RPKM) } & \multirow[b]{2}{*}{$p$-value } & \multirow[b]{2}{*}{ Fold change } & \multicolumn{2}{|c|}{15 DAA (RPKM) } & \multirow[b]{2}{*}{$p$-value } & \multirow[b]{2}{*}{ Fold change } & \multicolumn{2}{|c|}{20 DAA (RPKM) } & \multirow[b]{2}{*}{$p$-value } & \multirow[b]{2}{*}{ Fold change } \\
\hline & & $\overline{N G}$ & RNAi & & & $\overline{\mathrm{NG}}$ & RNAi & & & $\overline{N G}$ & RNAi & & \\
\hline LOC_Os05g26377 & PROLM9 - precursor, expressed & 10.42 & 34.97 & $3.33 \mathrm{E}-4$ & 3.355 & 6.14 & 13.75 & 0.00 & 2.241 & 13.93 & 48.11 & 0.00 & 3.452 \\
\hline LOC_Os03g07226 & Thioredoxin, putative, expressed & 176.08 & 87.9 & 0.02 & -2.00 & 234.84 & 134.73 & $2.16 \mathrm{E}-07$ & -1.743 & 431 & 74.28 & 0.00 & -1.488 \\
\hline LOC_Os05g26770 & PROLM18- precursor, expressed & 144 & 391.26 & $5.56 \mathrm{E}-5$ & 2.717 & 252.1 & 397.94 & $1.21 \mathrm{E}-05$ & 1.578 & 783.1 & 2001.73 & 0.01 & 2.556 \\
\hline LOC_Os06g31070 & PROLM24 precursor, expressed & 7999.23 & 6629.43 & 0.03 & -1.206 & 13109.13 & 8339.18 & 0.01 & -1.571 & 21612.21 & 13605.77 & 0.01 & -1.588 \\
\hline LOC_Os01g60410 & Ubiquitinconjugating enzyme & 392.22 & 271.47 & 0.02 & -1.444 & 258.38 & 153.13 & 1.55E-05 & -1.687 & 182.23 & 133.27 & 0.02 & -1.367 \\
\hline LOC_Os03g55730 & $\begin{array}{l}\mathrm{SSA} 2-2 \mathrm{~S} \text { albumin seed } \\
\text { storage family protein precursor }\end{array}$ & 7010.17 & 4731.88 & 4.97E-4 & -1.481 & 7616.26 & 4233.57 & 0.01 & -1.799 & 8507.59 & 5390.14 & 0.02 & -1.578 \\
\hline LOC_Os05g33570 & $40 S$ ribosomal protein $59-2$ & 807.34 & 510.12 & 0.01 & -1.582 & 402.52 & 183.09 & 5.65E-10 & -2.198 & 99.06 & 61.26 & 0.04 & -1.617 \\
\hline
\end{tabular}

DAA- days after anthesis 


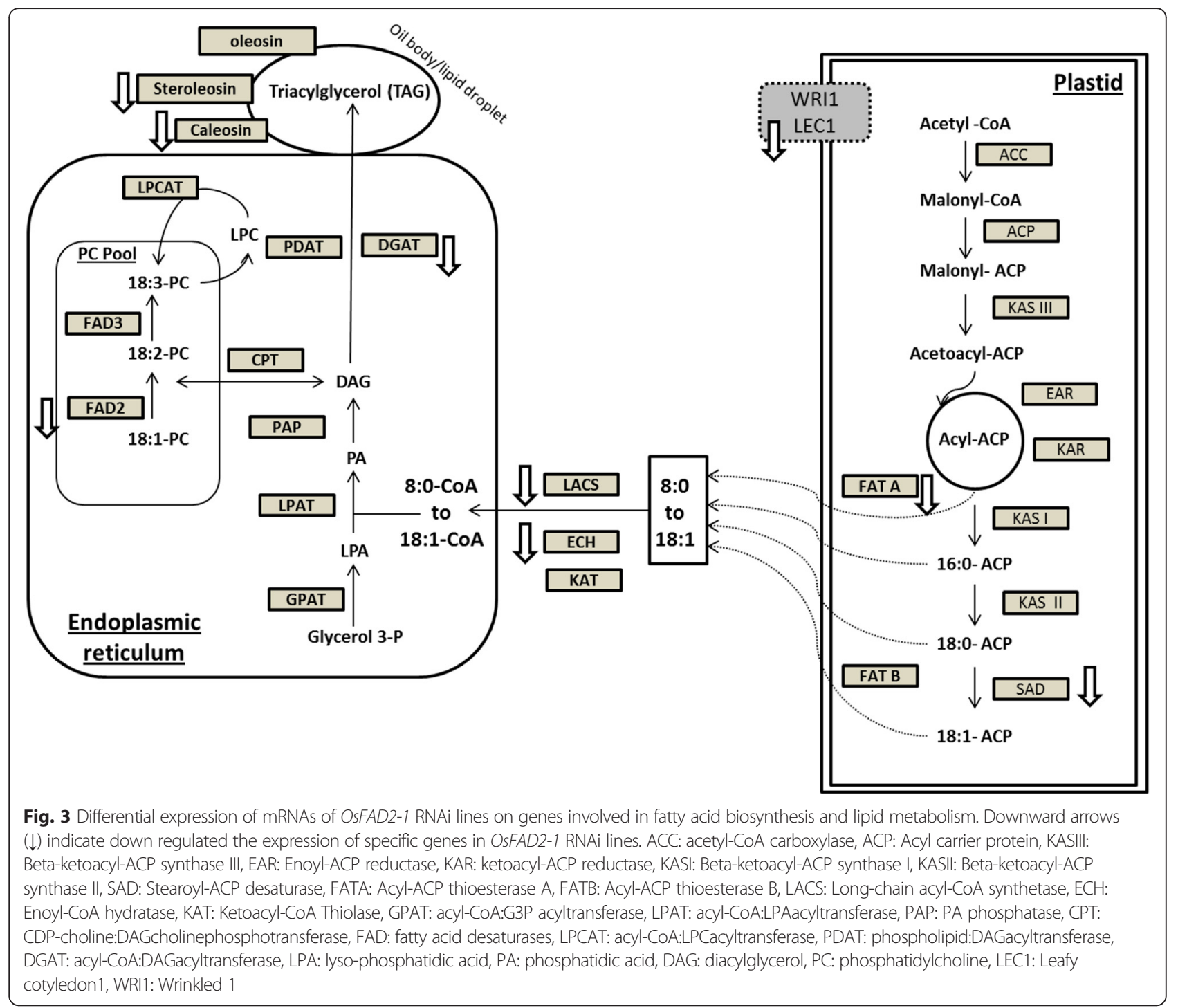

ethanol and kept at $-20{ }^{\circ} \mathrm{C}$ for $2 \mathrm{~h}$. Samples were centrifuged, rinsed with $70 \%$ ethanol and air dried as above. After drying, RNAs were dissolved in $20 \mu \mathrm{L}$ DEPC water, and treated with RQ1 RNase-Free DNase (Promega, Madison, WI) following protocols. The quality of RNA samples were measured with Nanodrop 1000 Spectrophotometer for the ratios of OD $260 \mathrm{~nm} / 280 \mathrm{~nm}(\geq 1.8)$ and OD260 $\mathrm{nm} / 230 \mathrm{~nm}(\geq 1.8)$ and with Aligent Bioanalyser for RNA integrity number $(\mathrm{RIN} \geq 6.5)$ score. RNA was normalised to $1 \mu \mathrm{g}$ starting amounts in $50 \mu \mathrm{L}$. Sequencing libraries were prepared using the NEBNext ${ }^{\circ}$ Ultra ${ }^{\text {Txt }}$ RNA Library Prep Kit for Illumina (New England Biolabs Inc., Ipswich, MA) following manufacturer's instructions. Quantification and size estimation of libraries were performed on a Bioanalyser 2100 High Sensitivity DNA chip (Agilent Technologies, Waldbronn, Germany). Libraries were finally normalised to 2nM and sequenced on the Miseq System (Illumina Inc., San Diego, USA) generating 150 bp length single end reads.
Transcriptomic analysis of OSFAD2 genes from published databases

Six rice RNAseq libraries were down-loaded from Rice Gnome Annotation Project [25] that contains RNAseq databases from different tissues of Nipponbare rice. The RNAseq libraries were named SRR352184, 352187, 352190, 342204, 352206 and 352207 and derived from 20 day leaves, post-emergence inflorescence, anthers, 25 DAA embryo, 25 DAA endosperm and 10 DAA grain respectively. The read lengths were 40 or $35 \mathrm{bp}$ and each run produced about 25 million 'clean' reads.

Four rice FAD2 genes, OsFAD2-1 to OsFAD2-4, were used as reference sequences to conduct gene mapping search "Map to Reference" against the databases in Additional file 6: Table S2 using a bioinformatic analysis program, Geneious [52]. Parameters used were set as custom sensitivity (for sensitivity), and none (fast/read mapping) (for Fine Tuning). Advanced settings were used with $10 \%$ gap, 25 bp 
minimum overlap, 24 word length (words repeated more than 8 times were ignored), $2 \%$ maximum mismatches per read, maximum gap 3, minimum overlap identity $80 \%$, index word length 14 and maximum ambiguity 4 .

\section{Statistics analysis}

Analysis of variation was performed using Genstat version 16 for lipid content and oleic acid content. All transcriptomics data of $\mathrm{HO}$ rice line and its null segregant was analysed using Qiagen CLC Genomics Workbench version 7.0.4. All statistical analysis was done using IBM SPSS Statistics version 20 and CLC Baggerley's test (CLC BioQiagen, Aarhus, Denmark). Details regarding the RNAseq analysis are available online athttp://www.clcbio.com/sup port/tutorials. For further verifying those differentially expressed genes determined by the method above, the read numbers for each cDNA were first converted to reads per kilo base per million (RPKM), then the ratios of RNAi and WT, and finally $\log 2$ value of the ratios.

\section{RNA extraction and quantitative real-time PCR (qRT-PCR)}

Total RNA from endosperms at 10, 15 and 20 DAA was extracted using NucleoSpin ${ }^{\circ}$ RNA Plant Kit (MachereyNagel, Duren, Germany) and quantified using Nanodrop1000 (Thermo Fisher Scientific, Waltham, MA). A total of $0.5 \mu \mathrm{g}$ of RNA templates was used for the cDNA synthesis in a $50 \mu \mathrm{L}$ reaction with ramp at $50{ }^{\circ} \mathrm{C}$ using Super Script III reverse transcriptase (Thermo Fisher Scientific). The cDNA template $(100 \mathrm{ng})$ was used in a $10 \mu \mathrm{L}$ qRT-PCR reaction with the annealing temperature at $58{ }^{\circ} \mathrm{C}$. The primers for ECH1 gene were ECH1F $(5$ ' GATGCTGGCGTTGCAAAGAT3') and ECH1R (5'TCCCTGCTTCTCAGCAAAAC A3'), for LACS gene were LACSF (5'TTGGCGAGGATGCACTGG 3') and LACSR (5'TGGAACTGATTGCAGGTAGCTT 3') which only amplified RT-PCR fragment in cDNAs. The primers for the Tubulin gene in rice were used as published [54]. The amplification was conducted in a Rotor-Gene 6000 (Corbett Life Sciences, Sydney, Australia) using Rotor Gene ${ }^{\mathrm{rm}}$ SYBR $^{\circ}$ Green PCR Kit (Qiagen, Hilden, Germany). Comparative quantification was analysed using Tubulin as a reference gene in the Real Time Rotary Analyzer Software (Corbett Life Sciences, Sydney, Australia). For each sample, triplicates of qRTPCR reactions were performed.

\section{Additional files}

Additional file 1: Amounts and fatty acid profiles of various lipids in Fad2 silenced rice. (XLSX $31 \mathrm{~kb}$ )

Additional file 2: List of unigenes involved in Fatty acid biosynthesis and catabolism. (XLSX $12 \mathrm{~kb}$ )

Additional file 3: List of unigenes involved in TAG acid biosynthesis and catabolism. (XLSX $14 \mathrm{~kb}$ )

Additional file 4: Table S1. (DOCX $17 \mathrm{~kb}$ )
Additional file 5: Gene expression (RPKM) values of affected genes in Lipid biosynthesis pathway. (XLSX $44 \mathrm{~kb}$ )

Additional file 6: Table S2. (DOC $30 \mathrm{~kb}$ )

Additional file 7: Figure S1. (DOCX $122 \mathrm{~kb}$ )

Funding

We thank Monash University, Malaysia for research funding and the Monash University Malaysia Tropical Medicine and Biology Platform for partially funding this study.

\section{Availability of data and materials}

All the supporting data are included as additional files in this manuscript.

\section{Authors' contribution}

GJT, QL, ZL, SR contributed to the design of the research. GJT carried out the RNA analysis with the help of the Monash University Genomics Facility with RNA provided by ZL. PS carried out the lipid analysis, GJT, QL, PS, ZL, SR contributed to the analysis of the results and writing the manuscript.

All authors have read and approved the final version of the manuscript.

Competing interests

The authors declare that they have no competing interests.

Consent for publication

Not applicable.

Ethics approval and consent to participate

No ethics approval was needed for this study.

Author details

${ }^{1}$ School of Science, Monash University Malaysia, 46150 Bandar Sunway, Selangor, Malaysia. ${ }^{2}$ Monash University Malaysia Genomics Facility, 46150 Bandar Sunway, Selangor, Malaysia. ${ }^{3}$ CSIRO Agriculture \& Food, PO Box 1600, Canberra, ACT 2601, Australia.

Received: 9 July 2016 Accepted: 24 August 2016

Published online: 31 August 2016

References

1. Maclean JL. Rice almanac: Source book for the most important economic activity on earth. Int Rice Res Inst. 2002.

2. Juliano B. Lipids in rice and rice processing. Lipids Cereal Technol. 1983;440. http://www.sciencedirect.com/science/article/pii/B9780120790203500210.

3. Sugano M, Tsuji E. Rice bran oil and cholesterol metabolism. J Nutr. 1997;127(3):521S-4S

4. Yoshida H, Tanigawa T, Kuriyama I, Yoshida N, Tomiyama Y, Mizushina Y. Variation in fatty acid distribution of different acyl lipids in rice (Oryza sativa L.) brans. Nutrients. 2011;3(4):505-14.

5. Carroll L. Functional properties and applications of stabilized rice bran in bakery products. Food Technol. 1990;44(4):74-6.

6. Orthoefer FT. Rice bran oil: healthy lipid source. Food Technol. 1996; 50(12):62-4.

7. MCCASKILL DR, Zhang F. Use of rice bran oil in foods: Developing nutraceuticals for the new millenium. Food Technol. 1999;53(2):50-3.

8. Lai P, Li KY, Lu S, Chen HH. Phytochemicals and antioxidant properties of solvent extracts from Japonica rice bran. Food Chem. 2009;117(3):538-44.

9. Taira H, Nakagahra M, Nagamine T. Fatty acid composition of Indica, Sinica, Javanica, Japonica groups of nonglutinous brown rice. J Agric Food Chem. 1988;36(1):45-7.

10. Radcliffe JD, Imrhan VL, Hsueh AM. The use of soy protein isolate to reduce the severity of 13-cis retinoic acid-induced hypertriglyceridemia. Cancer Detect Prev. 1997;22(6):526-32

11. Spiteller G. Linoleic acid peroxidation-the dominant lipid peroxidation process in low density lipoprotein-and its relationship to chronic diseases. Chem Phys Lipids. 1998;95(2):105-62.

12. Chaiyasit W, Elias RJ, McClements DJ, Decker EA. Role of physical structures in bulk oils on lipid oxidation. Crit Rev Food Sci Nutr. 2007;47(3):299-317.

13. Zhou Z, Robards K, Helliwell S, Blanchard C. Composition and functional properties of rice. Int J Food Sci Technol. 2002;37(8):849-68. 
14. Mauger J-F, Lichtenstein AH, Ausman LM, Jalbert SM, Jauhiainen M, Ehnholm C, et al. Effect of different forms of dietary hydrogenated fats on LDL particle size. Am J Clin Nutr. 2003;78(3):370-5.

15. Esmaillzadeh A, Azadbakht L. Consumption of hydrogenated versus nonhydrogenated vegetable oils and risk of insulin resistance and the metabolic syndrome among Iranian adult women. Diabetes Care. 2008; 31(2):223-6.

16. Benatar JR, Gladding P, White HD, Zeng I, Stewart RA. Trans-fatty acids in New Zealand patients with coronary artery disease. Eur J Cardiovasc Prev Rehabil. 2011;18(4):615-20.

17. U.S. Food and Drug Administration. [http://www.fda.gov/ForConsumers/ ConsumerUpdates/ucm372915.htm].

18. Zaplin ES, Liu Q, Li Z, Butardo VM, Blanchard CL, Rahman S. Production of high oleic rice grains by suppressing the expression of the OsFAD2-1 gene. Funct Plant Biol. 2013:40(10):996-1004

19. Weselake R, Shah S, Tang M, Quant PA, Snyder CL, Furukawa-Stoffer TL, et al. Metabolic control analysis is helpful for informed genetic manipulation of oilseed rape (Brassica napus) to increase seed oil content. J Exp Bot. 2008:59(13):3543-9.

20. Xu J, Francis T, Mietkiewska E, Giblin EM, Barton DL, Zhang Y, et al. Cloning and characterization of an acyl-CoA-dependent diacylglycerol acyltransferase 1 (DGAT1) gene from Tropaeolum majus, and a study of the functional motifs of the DGAT protein using site-directed mutagenesis to modify enzyme activity and oil content. Plant Biotechnol J. 2008;6(8):799-818.

21. Jako C, Kumar A, Wei Y, Zou J, Barton DL, Giblin EM, et al. Seed-specific overexpression of an Arabidopsis cDNA encoding a diacylglycerol acyltransferase enhances seed oil content and seed weight. Plant Physiol. 2001;126(2):861-74.

22. Clemente TE, Cahoon EB. Soybean oil: genetic approaches for modification of functionality and total content. Plant Physiol. 2009;151(3):1030-40.

23. Taylor DC, Zhang Y, Kumar A, Francis T, Giblin EM, Barton DL, et al. Molecular modification of triacylglycerol accumulation by over-expression of DGAT1 to produce canola with increased seed oil content under field conditions This paper is one of a selection of papers published in a Special Issue from the National Research Council of Canada-Plant Biotechnology Institute. Botany. 2009;87(6):533-43.

24. Van Erp H, Bates PD, Burgal J, Shockey J. Castor phospholipid: diacylglycerol acyltransferase facilitates efficient metabolism of hydroxy fatty acids in transgenic Arabidopsis. Plant Physiol. 2011;155(2):683-93.

25. MSU Rice Genome Annotation Project. [http://rice.plantbiology.msu. edu/index.shtml]

26. Hiltunen JK, Schonauer MS, Autio KJ, Mittelmeier TM, Kastaniotis AJ, Dieckmann CL. Mitochondrial fatty acid synthesis type II: more than just fatty acids. J Biol Chem. 2009;284(14):9011-5.

27. Hiltunen JK, Autio KJ, Schonauer MS, Kursu VS, Dieckmann CL, Kastaniotis AJ. Mitochondrial fatty acid synthesis and respiration. Biochim Biophys Acta Bioenergetics. 2010;1797(6):1195-202.

28. Salas JJ, Ohlrogge JB. Characterization of substrate specificity of plant FatA and FatB acyl-ACP thioesterases. Arch Biochem Biophys. 2002;403(1):25-34.

29. Wang L, Yu S, Tong C, Zhao Y, Liu Y, Song C, et al. Genome sequencing of the high oil crop sesame provides insight into oil biosynthesis. Genome Biol. 2014;15(2):1.

30. Theodoulou FL, Eastmond PJ. Seed storage oil catabolism: a story of give and take. Curr Opin Plant Biol. 2012;15(3):322-8.

31. Vanhercke T, El Tahchy A, Liu Q, Zhou XR, Shrestha P, Divi UK, et al. Metabolic engineering of biomass for high energy density: oilseed-like triacylglycerol yields from plant leaves. Plant Biotechnol J. 2014;12(2):231-9.

32. Lung S-C, Weselake RJ. Diacylglycerol acyltransferase: a key mediator of plant triacylglycerol synthesis. Lipids. 2006;41(12):1073-88.

33. Bates PD. The significance of different diacylgycerol synthesis pathways on plant oil composition and bioengineering. Frontiers Plant Sci. 2012;3:147.

34. Beaudoin F, Napier JA. 8 Biosynthesis and compartmentation of triacylglycerol in higher plants. Lipid Metabolism and Membrane Biogenesis: Springer; 2004. p. 267-87.

35. Coleman RA, Lee DP. Enzymes of triacylglycerol synthesis and their regulation. Prog Lipid Res. 2004;43(2):134-76.

36. Stobart K, Mancha M, Lenman M, Dahlqvist A, Stymne S. Triacylglycerols are synthesised and utilized by transacylation reactions in microsomal preparations of developing safflower (Carthamus tinctorius L.) seeds. Planta. 1997;203(1):58-66.

37. Kroon JT, Wei W, Simon WJ, Slabas AR. Identification and functional expression of a type 2 acyl-CoA: diacylglycerol acyltransferase (DGAT2) in developing castor bean seeds which has high homology to the major triglyceride biosynthetic enzyme of fungi and animals. Phytochemistry. 2006;67(23):2541-9.
38. Abbadi A, Domergue F, Bauer J, Napier JA, Welti R, Zähringer U, et al. Biosynthesis of very-long-chain polyunsaturated fatty acids in transgenic oilseeds: constraints on their accumulation. Plant Cell. 2004;16(10):2734-48.

39. Cahoon EB, Shockey JM, Dietrich CR, Gidda SK, Mullen RT, Dyer JM. Engineering oilseeds for sustainable production of industrial and nutritional feedstocks: solving bottlenecks in fatty acid flux. Curr Opin Plant Biol. 2007;10(3):236-44.

40. Cagliari A, Margis-Pinheiro M, Loss G, Mastroberti AA, de Araujo Mariath JE, Margis R. Identification and expression analysis of castor bean (Ricinus communis) genes encoding enzymes from the triacylglycerol biosynthesis pathway. Plant Sci. 2010;179(5):499-509.

41. Shimada TL, Shimada T, Takahashi H, Fukao Y, Hara-Nishimura I. A novel role for oleosins in freezing tolerance of oilseeds in Arabidopsis thaliana. Plant J. 2008;55(5):798-809.

42. Siloto RM, Findlay K, Lopez-Villalobos A, Yeung EC, Nykiforuk CL, Moloney $\mathrm{MM}$. The accumulation of oleosins determines the size of seed oilbodies in Arabidopsis. Plant Cell. 2006;18(8):1961-74. http://www.sciencedirect.com. ezproxy.lib.monash.edu.au/science/article/pii/S0168945205003602.

43. Chepyshko H, Lai C-P, Huang L-M, Liu J-H, Shaw J-F. Multifunctionality and diversity of GDSL esterase/lipase gene family in rice (Oryza sativa L. japonica) genome: new insights from bioinformatics analysis. BMC Genomics. 2012;13(1):1.

44. Parcy F, Valon C, Raynal M, Gaubier-Comella P, Delseny M, Giraudat J. Regulation of gene expression programs during Arabidopsis seed development: roles of the ABI3 locus and of endogenous abscisic acid. Plant Cell. 1994;6(11):1567-82.

45. Stone SL, Kwong LW, Yee KM, Pelletier J, Lepiniec L, Fischer RL, et al. LEAFY COTYLEDON2 encodes a B3 domain transcription factor that induces embryo development. Proc Natl Acad Sci. 2001;98(20):11806-11.

46. Jakoby M, Weisshaar B, Dröge-Laser W, Vicente-Carbajosa J, Tiedemann J, Kroj T, et al. bZIP transcription factors in Arabidopsis. Trends Plant Sci. 2002;7(3):106-11.

47. Cernac A, Benning C. WRINKLED1 encodes an AP2/EREB domain protein involved in the control of storage compound biosynthesis in Arabidopsis. Plant J. 2004:40(4):575-85.

48. Braybrook SA, Stone SL, Park S, Bui AQ, Le BH, Fischer RL, et al. Genes directly regulated by LEAFY COTYLEDON2 provide insight into the control of embryo maturation and somatic embryogenesis. Proc Natl Acad Sci U S A. 2006:103(9):3468-73.

49. Dabbs P. Identification of Plant Transcription Factors that Play a Role in Triacylglycerol Biosynthesis. 2015

50. Vanhercke T, Wood CC, Stymne S, Singh SP, Green AG. Metabolic engineering of plant oils and waxes for use as industrial feedstocks. Plant Biotechnol J. 2013;11(2):197-210.

51. Higgins T, Goodwin PB, Whitfeld PR. Occurrence of short particles in beans infected with the cowpea strain of TMV: II. Evidence that short particles contain the cistron for coat-protein. Virology. 1976;71(2):486-97.

52. Geneious. [http://www.geneious.com]

53. Chen JC, Tsai CC, Tzen JT. Cloning and secondary structure analysis of caleosin, a unique calcium-binding protein in oil bodies of plant seeds. Plant Cell Physiol. 1999;40(10):1079-86.

54. Toyota K, Tamura M, Ohdan T, Nakamura Y. Expression profiling of starch metabolism-related plastidic translocator genes in rice. Planta. 2006;223(2):248-57.

55. Livak KJ, Schmittgen TD, Livak KJ, Schmittgen TD. Analysis of relative gene expression data using real-time quantitative PCR and the $2-\triangle \triangle C T$ method. Methods. 402-8;25(4).

\section{Submit your next manuscript to BioMed Central and we will help you at every step:}

- We accept pre-submission inquiries

- Our selector tool helps you to find the most relevant journal

- We provide round the clock customer support

- Convenient online submission

- Thorough peer review

- Inclusion in PubMed and all major indexing services

- Maximum visibility for your research

Submit your manuscript at www.biomedcentral.com/submit 